\title{
Implementasi Aplikasi Elektronik Data Badan Usaha (E-Dabu) Dalam Pelayanan Kepesertaan Jamkesda di Kelurahan Duri Pulo Jakarta Pusat
}

\author{
Syukron Sazly1, Himawan Pratama 2 \\ 1,2 Administrasi Bisnis, Universitas Bina Sarana Informatika \\ Indonesia \\ e-mail:syukron.szy@bsi.ac.id,himawan.pratama0207@gmail.com
}

\begin{abstract}
Regional Health Insurance (Jamkesda) is a health service assistance guarantee program whose contributions are given by the Provincial Government to underprivileged residents who do not yet have any health insurance. In its implementation, Duri Pulo Village as one of the government agencies under the auspices of the Provincial Government of DKI Jakarta uses the Electronic Data Application for Business Entity (E-Dabu). E-Dabu application is an application that will make the service process in Jamkesda more effective and efficient because this application allows business entity or government institutionas a partner BPJS Health can register, update or change a large amount of participant data and approve registration of participants Jamkesda without waiting for BPJS Health approval as the organizer. This study aims to determine how the implementation of Electronic Data Applications for Business Entity (E-Dabu) undertaken, the benefits, constraints and solutions happened. The results of this study indicate that the implementation is going well, in accordance with the guidelines for using the application, so that the Duri Pula Village Office receives significant benefits from the implementation of the E-Dabu application.
\end{abstract}

Keywords: Implementation, E-Dabu Application, Jamkesda

\begin{abstract}
Abstrak - Jaminan Kesehatan Daerah (Jamkesda) merupakan program jaminan bantuan pelayanan kesehatan yang iurannya diberikan Pemerintah Provinsi kepada warga kurang mampu yang belum memiliki jaminan kesehatan apapun.Dalam pelaksanaannya, Kelurahan Duri Pulo sebagai salah satu instansi pemerintah di bawah naungan Pemerintah Provinsi DKI Jakarta menggunakan Aplikasi Elektronik Data Badan Usaha (E-Dabu).Aplikasi E-Dabu adalah sebuah aplikasi yang akan membuat proses pelayanan dalam Jamkesda menjadi lebih efektif dan efisien karena aplikasi ini memungkinkan suatu badan usaha atau instansi pemerintan sebagai mitra BPJS Kesehatan dapat mendaftarkan, memperbaharui atau mengubah data data peserta dalam jumlah banyak secara massal serta menyetujui pendaftaran peserta Jamkesda tanpa menunggu persetujuan BPJS Kesehatan sebagai penyelenggara. Penelitian ini bertujuan untuk mengetahui bagaimana implementasi Aplikasi Elektronik Data Badan Usaha (E-Dabu) tersebut,manfaat, kendala dan solusinya. Hasil penelitian ini menunjukkan implememtasi berjalan dengan baik, sesuai dengan pedoman penggunaan aplikasi, sehingga Kantor Kelurahan Duri Pula memperoleh manfaat yang signifikan dari implementasi aplikasi E-Dabu tersebut.
\end{abstract}

Kata Kunci:Implementasi, Aplikasi E-Dabu, Jamkesda 


\section{PENDAHULUAN}

Pemberian pelayanan untuk mendapatkan jaminan kesehatan sangatlah penting guna tmenjaminkesehatan bagi seluruh masyarakat.Untuk memenuhi dan mewujudkan hak bagisetiap warga negara terkait dengan pelayanan kesehatan yang layak agar dapat bekerja produktif dan hidup bermartabat maka pemerintah dalam hal ini Pemerintah Pusat maupun Pemerintah Daerah (PEMDA) sama-sama bertanggung jawab dalam upaya memelihara serta juga mempertinggi derajat kesehatan masyarakatIndonesia tersebut.

Terkait dengan hal diatas, Pemerintah Indonesia menyelenggarakan beberapa bentuk jaminan sosial kesehatan, di antaranya adalah melalui PT Askes (Persero) dan PT Jamsostek (Persero).Mulai tanggal 1 Januari 2014, PT Askes Indonesia(Persero) berubah nama menjadi BPJSKesehatan sesuai dengan Undang-Undang Nomor 24Tahun 2011 tentang BPJS. Melalui Undang-Undang Nomor 24 Tahun 2011, Pemerintah Indonesia menyelenggarakan BPJS Kesehatan untuk menciptakan masyarakat yang sehat jasmani danrohani.Salah satu dari beberapa bentuk jaminan sosial kesehatanyang diselenggarakan olehPemerintah Indonesia melalui BPJS Kesehatan adalah jaminan kesehatan daerah. Jaminan kesehatan daerah merupakan program jaminan bantuan pelayanankesehatan yang iurannyadiberikanoleh Pemerintah

Provinsi atau Daerah untuk menyasar kepada warga kurang mampu yang samasekalibelum memiliki jaminan kesehatanapapun. Dengan diluncurkannya program jaminan kesehatandaerah, diharapkan mampu mengatasi sedikit permasalahan tentang pemberian pelayanan untuk mendapatkan jaminankesehatan secara gratis yang dianggap sulit untuk didapatkan oleh warga kurang mampu saatini.

Untuk mendukung kelacaran pelayanan Jamkesda tersebut, BPJS Kesehatan meluncurkan aplikasi yang dinamakan Elektronik Data Badan Usaha atau EDabu BPJS Kesehatan.Tujuan dari penelitian ini adalah untuk mengetahui bagaimana implementasi aplikasi EDabu dapat membantu pelayanan kepesertaan Jasmkesda di Kelurahan Duri Pulo, Jakarta Pusat.

\section{BAHAN DAN METODE}

\section{Aplikasi E-Dabu}

Aplikasi E-Dabu adalah sebuah aplikasi yang akan membuat proses pelayanan dalam Jamkesda menjadi lebih efektif dan efisien karena aplikasi ini memungkinkan suatu bada usaha atau lembaga mendaftarkan, memperbaharui atau mengubah data data peserta dalam 
jumlah banyak secara massal, tidak satu persatu seperti sebelumya. Aplikasi E-dabu ini sangat bermanfaat untuk mendukung perusahaan atau lembaga yang jumlah pegawainya cukup besar, sehingga tidak akan terjadi antrian jika karyawan tersebut mendaftar satu persatu ke kantor BPJS Kesehatan.

\section{Fasilitas Aplikasi E-Dabu}

Terdapat beberapa fasilitas yang ada dalam aplikasi E-Dabu ini , antara lain;

1. Cek data peserta Jamkesda.Fitur ini digunakan oleh user aplikasiE-Dabu yang telah ditunjuk dan berhak untuk melakukan login. Fitur ini akanbisa membuat pengecekan status kepesertaan Jamkesda menjadi semakin mudah.

2. Mengubah Data atau Profil Peserta.Perubahan data tersebut bisa berupa perubahan profil atau penambahan anggota keluarga, penambahan peserta dan mutasi peserta.

3. Pendaftaran Peserta Secara Massal.Fitur ini yang paling dirasakan manfaatnya khususnya bagi lembaga atau perusahaan yang memiliki banyak karyawan. Cukup dengan menyiapkan data karyawan dalam format Microsoft Excel maka seluruh data calon peserta Jamkesda dalam file tersebut akan terdaftar secara otomatis .
4. Online Approval. Fitur ini memberikan kewenangan untuk memberikan pilihan kepada petugas yang telah ditunjuk untuk langsung memberikan persetujuan kepesertaan Jamkesda jika data-data sudah dinyatakan lengkap.

5. Cek Kartu dan Rekap Tagihan.Aplikasi ini juga memiliki fitur untuk mengecek rekap tagihan bulanan dari peserta Jamkesda Kesehatan yang telah didaftarkan.

\section{Pelayanan}

Menurut Kotler dalam (Daryanto \&Setyobudi, 2014) mendefinisikan bahwa, Pelayanan adalah setiap kegiatanyang menguntungkandalam suatu kumpulan atau kesatuan, dan menawarkan kepuasan meskipun hasilnya tidak terikat pada suatu produk secarafisik.

Menurut (Riyanto, 2018), Pelayanan merupakan salah satu bentuk kegiatan atau aktifitas yang diberikan oleh satu pihak atau lebih kepadapihak lain yang memiliki hubungan dengan tujuan untuk dapat memberikan kepuasan kepada pihak kedua yang bersangkutan atas barang dan jasa yangdiberikan.Ivancevich dkk dalam (Mukarom \&Laksana ， 2015) mendefinisikanPelayanan adalah produk yang tidak kasat mata yang melibatkan usaha-usaha manusia dan 
menggunakanperalatan.

\section{JenisPelayanan}

H.A.S.Moenir dalam (Umam , 2014) membagi pelayanan secara umum menjadi dua jenis utama,yaitu; pelayanan fisik, yang sifatnya pribadi sebagaimanusia dan pelayanan administratif, yangdiberikan oleh orang lain selaku anggota organisasi

\section{PrinsipPelayanan}

Berry dalam (Patmiarsih dkk, 2014) mengatakan bahwa dalam pelayanan terdapat prinsip yang dinilai terhadap pelayanan,yaitu:tampilan fasilitasfisik, personil, komunikasi, ketepatan dan kecepatan, ketanggapan dan Jaminan serta perhatian individual

\section{PelayananPublik}

Menurut Ridwan dan Sudrajat dalam (Sugiyah, 2018), pelayanan publik merupakan pelayanan yang diberikan oleh pemerintah terhadap masyarakatnya guna memenuhi kebutuhandan memiliki tujuan untuk meningkatkan kesejahteraanmasyarakat.

Menurut Ratminto dalam (Khalil S, 2016), pelayanan publik adalahsegala bentuk jasa pelayanan, baik dalam bentuk barang publik maupun jasa publik yang pada prinsipnyamenjadi tanggung jawabdan dilaksanakan oleh instansi pemerintah di pusat, di daerah, dan di lingkungan Badan Usaha Milik Negara atau Badan Usaha Milik Daerah, dalam rangka upaya pemenuhan kebutuhan masyarakat.

\section{Unsur PelayananPublik}

Menurut Kasmir dalam(Maryam , 2016)ciri-ciri pelayanan publik yang baik adalah memiliki unsur-unsur sebagaiberikut:

1. Tersedianya karyawan serta sarana dan prasarana yangbaik

2. Bertanggung jawab dan mampu melayani secara cepat dantepat.

3. Mampuberkomunikasi dan menjamin kerahasiaan setiaptransaksi.

4. Memiliki pengetahuan dan kemampuan yangbaik, memahami kebutuhan nasabahdan ampu memberikan kepercayaan.

\section{Tujuan PelayananPublik}

Tujuan Pelayan publik pada Pasal 3 Undang-Undang Nomor 25 tahun 2009 dalam (Mukarom \&Laksana, 2015) tentang Pelayanan Publik adalah:

1. Terwujudnya batasan dan hubungan yang jelas tentang hak, tanggung jawab, kewajiban, dan kewenanganseluruh pihak yang terlibat.

2. Terwujudnya sistempenyelenggaraan pelayanan publik yang layak

3. Terwujudnya perlindungan dankepastian hukum bagimasyarakat dalam pelayananpublik.

\section{HASIL DAN DISKUSI}

Kelurahan Duri Pulo yang 
beradadiwilayahKota AdministrasiJakarta

Pusat merupakan salah satu wilayah Kelurahan yang padat penduduknya dengan beragam etnis suku bangsa. Kondisi seperti ini dengan sendirinyamenimbulkan masalah sosial kemasyarakatan yang kompleks, mengingat hal tersebut dibutuhkan aparat Dengan luas wilayah 70,71 Ha, yang di huni oleh 25.059 jiwa, dengan batas wilayah J1, KH Zainul Arifin (sebelah Utara),Kali Cideng (Sebelah Timur), Jl, KH.Hasyim Ashari (sebelah Selatan ) dan Kali Banjir Kanal (sebelah Barat), diperlukan Pemerintah Kelurahan yang cekatan,berdedikasi, dan senantiasa harus meningkatkankinerjanya.. Kelurahan Duri Pulo merupakan Kelurahan yangberada di wilayah Kecamatan Gambirr. Karakteristikwilayah Kelurahan Duri Pulo adalah campuran antara pemukiman padat yang ada di 5 lingkungan RW dan sebagian lagi merupakan daerah bisnis perkantoran / pertokoan yang ada di2RW sedangkan sisanya di 3 RW. 85\% sudah menjadi lahan kosong sedangkan 15\% lagi masih dihuni oleh penduduk

yangmenungguprosespembebasanlahanyang rencana kedepannya akanmenjadi sentra bisnis. Uraian selengkapnya mengenai kondisi wilayah Kelurahan Duri Pulo sebagaiberikut: strukutr organisasidapat diketahui dengan jelas wewenangdan tugas sertatanggung jawabsetiap anggota organisasi atau pegawai.Kelurahan Duri Pulo mempunyai struktur organisasi yang tersusun rapi dan sesuai dengan tugas jabatan yang ditentukan.

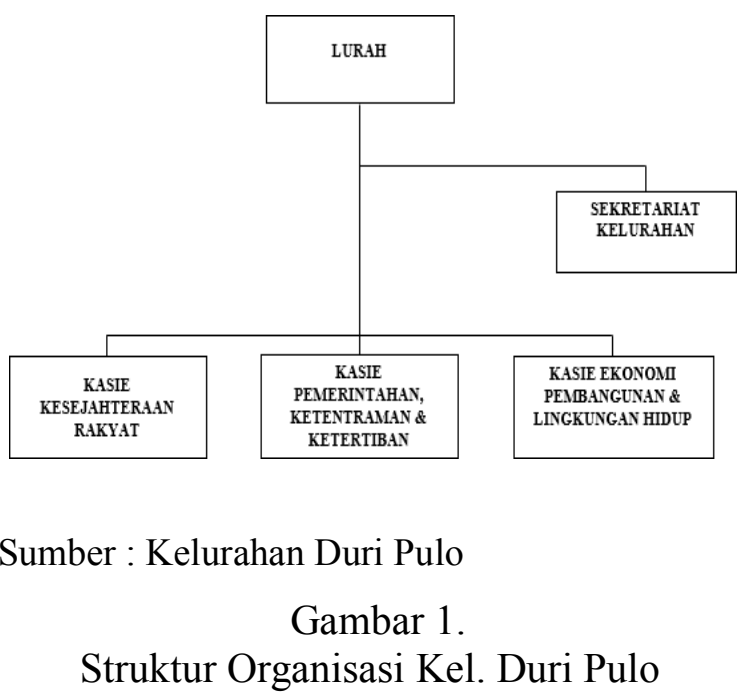

Aplikasi E-Dabu Dalam Pendaftaran Peserta Jamkesda.

Dalam melakukan pelaksanaan pelayananpendaftaran peserta Jamkesda DKI pada Kelurahan Duri Pulo, terdapat beberapa tahap-tahap pelaksanaan pelayanan pendaftaran yang dilakukan dan telah diatur sesuai dengan pedoman sosialisasi teknis pendaftaran JKN-KIS (Jaminan Kesehatan Nasional-Kartu Indonesia Sehat) Kelurahan untuk Jamkesda DKI pada gambar 2.di bawahini:

\section{Struktur Kelurahan Duri Pulo}

Struktur organisasi merupakan bagian yang sangat penting, oleh karena itu dengan adanya 


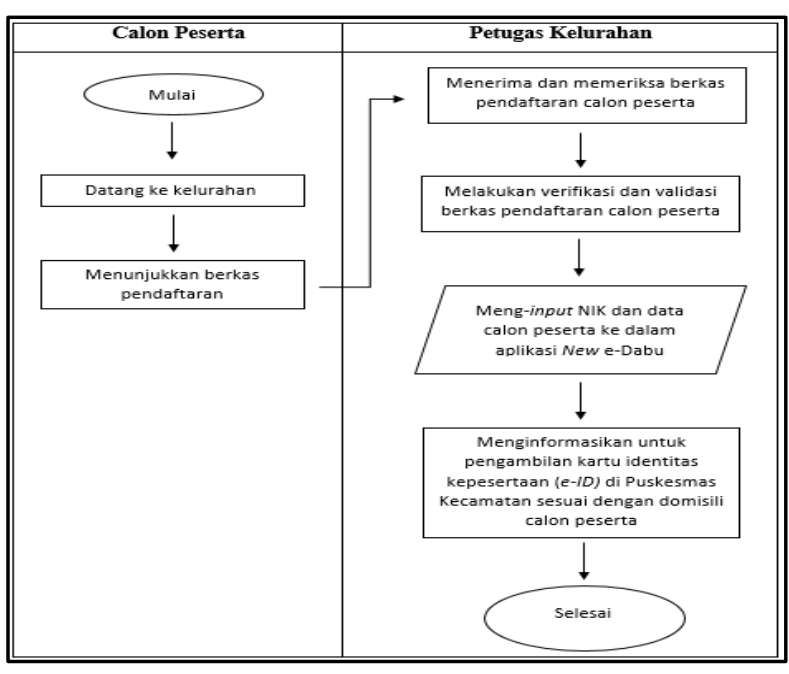

Sumber: Kelurahan Duri Pulo

Gambar 2.

Pelayanan Pendaftaran Jamkesda DKI

Pelaksanaan Pelayanan Pendaftaran JamkesdaDKI ;

1. Calon peserta datang ke kantor Kelurahan dan ingin melakukan pendaftaranpeserta Jamkesda DKI.

2. Calon peserta menunjukkan berkas pendaftaran kepada Petugas Kelurahan yang melayani pendaftaran Jamkesda DKI seperti fotokopi KK, e-KTP DKI ,fotokopi Akta Kelahiran nomor telepon atau handphone, dan alamat email.

3. Petugas Kelurahan melakukan verifikasi dan validasi berkas pendaftaran serta memastikan calon peserta tersebut..

4. Petugas Kelurahan meng-input NIK (Nomor Induk Kewarganegaraan) dan data calon peserta ke dalam aplikasi New e-Dabu yang diakses melaluijaringan internet publik dan terakses secara langsung ke Disdukcapil
Provinsi DKI Jakarta. New e-Dabu

(Elektronik Data Badan Usaha) merupakan sebuah aplikasi yang dibuat oleh tim BPJS dalam melakukan pelaksanaan pelayanan pendaftaran peserta Jamkesda Berikut ini merupakan langkah-langkah yang dilakukan oleh petugas Kelurahan untuk meng-input NIKdan data calon peserta pendaftaran peserta Jamkesda DKI ke dalam aplikasi e-Dabu, yaitu:

a. Buka aplikasi Newe-Dabu, lalu masukkan user dan password serta ketikan kode captcha yang tampil pada formlogin

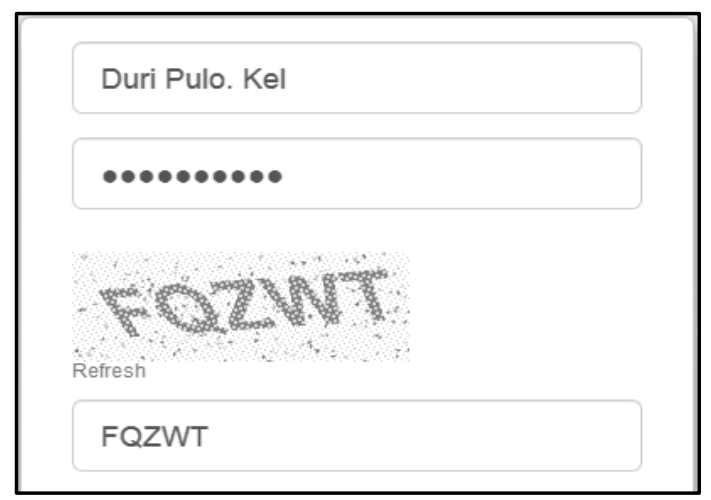

Sumber: Kelurahan Duri Pulo

Gambar 3.

Form Login New e-Dabu

b. Input data NIK, No.KK, nama, PISA (Peserta/Istri/Suami/Anak), tempat dan tanggal lahir, jenis kelamin, status kawin, No.Telp, email, RT, RW, kode pos, provinsi, DATI 2 kecamatan, dan desa. 


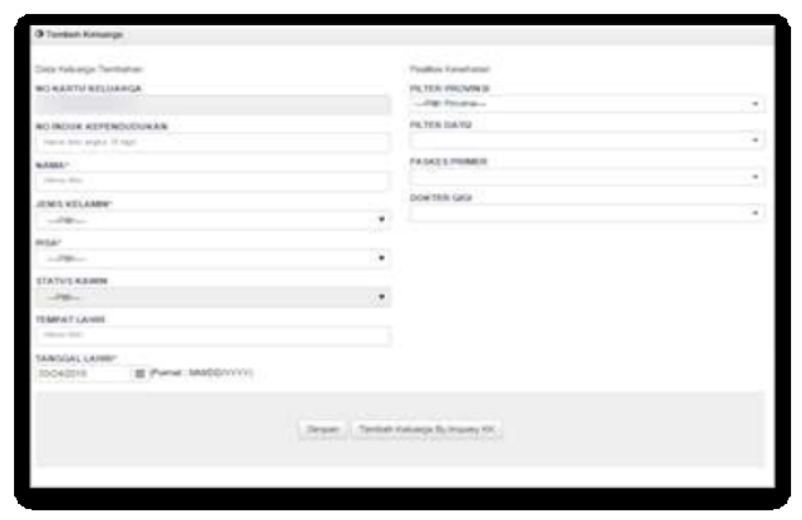

Sumber: Kelurahan DuriPulo

Gambar 4.

Form Entri Tabular Data Pribadi

c. Untuk input data peserta pada form entri tabularfasilitas kesehatan, masukkan filter provinsi, filter DATI 2 (Daerah Tingkat Dua), Faskes Primerdandoktergigi.

\begin{tabular}{|c|c|c|}
\hline \multicolumn{3}{|c|}{ Input Data Peserta } \\
\hline Data Pribadi & Fasilitas Kesehatan & \\
\hline \multicolumn{3}{|c|}{ FLLTER PROVINSI } \\
\hline \multicolumn{2}{|l|}{ DKI JAKARTA } & r \\
\hline \multicolumn{3}{|l|}{ FILTER DATI2 } \\
\hline \multicolumn{2}{|c|}{ KOTA JAKARTA PUSAT } & v \\
\hline \multicolumn{3}{|c|}{ FASKES PRIMER* } \\
\hline \multicolumn{2}{|c|}{ Kel. Duri Pulo } & v \\
\hline \multicolumn{3}{|l|}{ DOKTER GIG|* } \\
\hline \multicolumn{2}{|c|}{ Tanpa Dokter Gigi } & r \\
\hline
\end{tabular}

Sumber: Kelurahan Duri Pulo

Gambar 5.

Entri Fasilitas Kesehatan e-Dabu

d. Petugas Kelurahan menginformasikan untuk pengambilan kartu identitas kepesertaan (e-ID)paling lambat1 bulan pasca melakukan pendaftaran peserta Jamkesda DKI.

\section{Aplikasi E-Dabu Untuk Tambahan}

\section{Keluarga PesertaJamkesda}

Untuk melakukan penambahan anggota keluarga dengan cara entri manual,

a. Akses form tambah peserta entri manual

b. Masukan NIK anggota keluarga (16 digit angka). NIK tersebut akan divalidasilalu bila validasi lolos maka system akan inquery dengan data dukcapil.

c.Lengkapi data pada inputan form

d. Tekan tombol simpan.

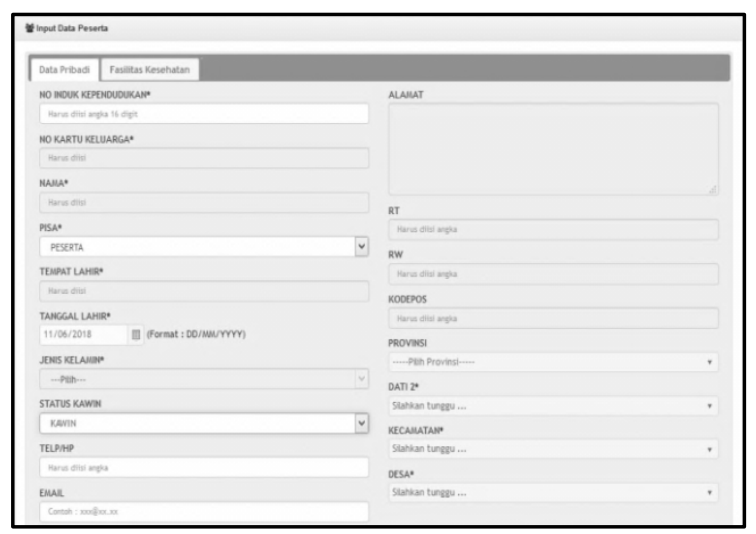

Sumber: Kelurahan Duri Pulo

Gambar 6.

Entri Penambahan Keluarga

\section{Aplikasi E-Dabu dalam Editing DataPeserta Jamkesda}

Untuk melakukan perubahan (edit) data peserta atau anggota keluarga, user dapat mengikuti prosedur berikut:

a. Usermenampilkanformpencarian pesertadenganmemilihmenudata pesertaedit datapeserta. 
b. User melakukan pencarian data peserta baik dengan memilih salah satu parameter atau menampilkan seluruhdata

c. User menekan tombol editpeserta.

d. User menyesuaikan data sesuai dengan keperluan.

e. User menekan tombolsimpan

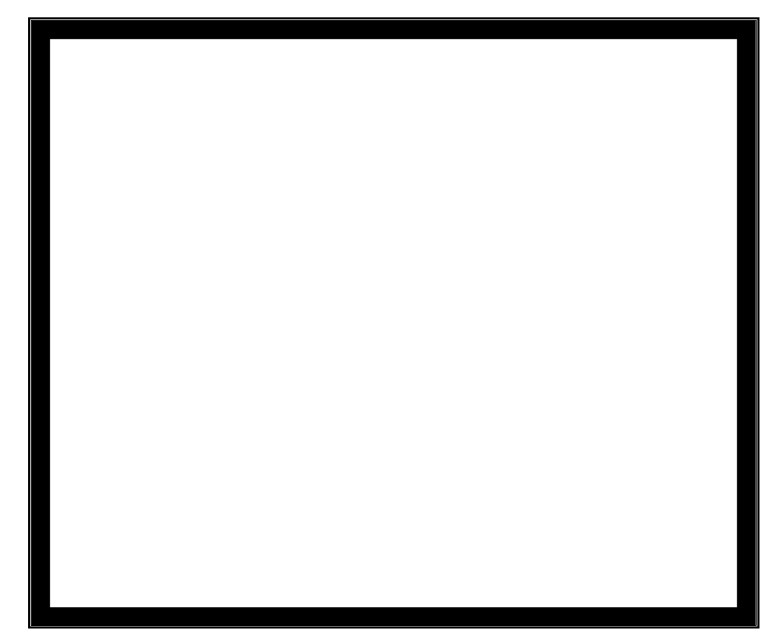

Sumber: Kelurahan Duri Pulo

Gambar 7.

Edit Data Peserta Jamkesda

\section{Aplikasi E-Dabu dalam Approval Peserta Jamkesda}

Berikut ini standar prosedur yang dilakukan untuk melakukan approval

a. Tentukan pilihan berdasarkan parameter-parameter yang tersedia pada form.

b. TekantombolLihatdata,setelahtomboldi tekanmakasistemakanmencari datadan menampilkandatatersebutdalam bentuk table.

c. Checklist pernyataan "Saya menyatakan dan menjamin bahwa semua informasi diatas adalah benar dan sah dalam segala hal dan saya tidak menyembunyikan fakta yang sesungguhnya”.

d. Tekan tombolapprove.

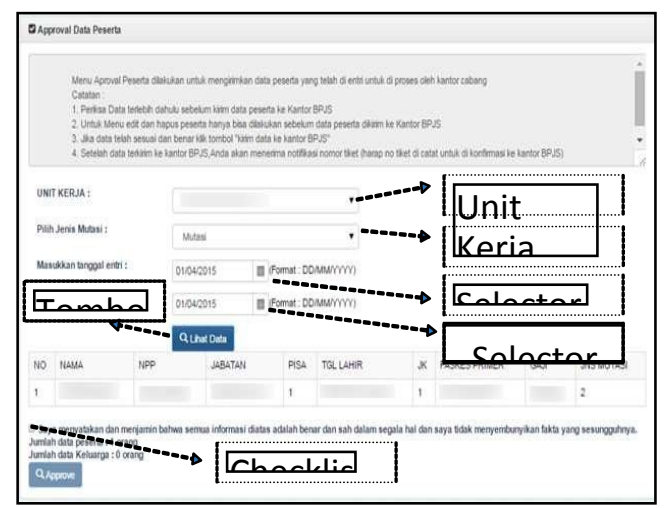

Sumber: Kelurahan Duri Pulo

Gambar 8. Approval Peserta Jamkesda

Melalui implementasi aplikasi E-Dabu, Jumlahpeserta yang telah melakukan pendaftaran peserta Jamkesda DKI sebagai peserta Penerima Bantuan Iuran (PBI) di bulan April 2018 sebanyak 19 peserta, yaitu dari RW.08 yakni berjumlah 5 peserta, RW.09 dengan jumlah 3 peserta, RW.012 yang berjumlah sama 3 peserta, RW.04 yakni dengan jumlah 2 pesertaserta RW.01 yakni hanya berjumlah 1 peserta 
Manfaat Implementasi Aplikasi E-

\section{Dabu Dalam Pelayanan Peserta}

Jamkesda.

Terdapat beberapa manfaat yang diperoleh dalam implementasi e-dabu ,yaitu:

1. Aplikasi ini menyediakan fitur bagi badan usaha untuk melakukan pendaftaran baru karyawanserta dapat melakukan perubahan data peserta.

2. Aplikasi New E-Dabu tersebut dapat diakses di mana saja.

3. E-Dabu dapat melakukan mutasi data peserta tanpa harus ke kantor BPJS Kesehatan.

4. E-Dabu dapat mengecek status kepesertaan, perubahan data peserta, ,mengubah fasilitas kesehatan tingkat pertama seperti puskesmas, klinik dan dokter praktik perorangan,

5. User E-Dabu dapat melakukan Approval pendaftaran kepesertaan tanpa harus menunggu persetujuan dari BPJS Kesehatan.

\section{Kendala Dalam Implementasi Aplikasi}

E-DabuDalamPelayanan Peserta Jamkesda.

Dalam melakukan pelaksanaan pelayananpendaftaran, terdapat beberapa kendala yang terjadi,yaitu:

1. Gagal ter-input dan tidak terprosesnya nomor KK karena beberapa peserta atau salah satu peserta dari anggota keluarga calon peserta dalam satu nomor KK tersebut sebelumnya telahmelakukan pendaftaranpeserta Jamkesda DKI sebagai peserta Penerima Bantuan Iuran (PBI) pada Kelurahan Duri Pulo JakartaPusat.

2. Saat petugas Kelurahan melakukan login pada aplikasi New e-Dabu terkadang sering mengalami erroratau gagal login, sertatidak valid nya username dan password setelah mengklik tombol sign in.

\section{KESIMPULAN}

Berdasarkan hasil penelitian di atas, dapat dsmpulkanlkan bahwa;

1. Implementasi Aplikasi E-Dabu sangat bermanfaat bagi berbagai pihak. Lembaga atau perusahaan yang tertentu dapat mendaftarkan pegawainya secara massal tanpa mereka harus datang ke kantor BPJS Kesehatan.

2. BPJS Kesehatan dapat memperoleh peserta baru yang bersifat massal tanpa mengalami antrian di kantor ataupenambahan SDM dan fasilitas lainnya.

3. Kendala yang terjadi ketika pelaksanaanpelayanan pendaftaran peserta Jamkesda DKI berlangsung 
yaitu gagal ter-input dan petugas

Kelurahan terkadang mengalamierror atau gagal login dan tidak valid-nya username dan password setelah mengklik tombol signing.

4. Cara mengatasi kendala,maka petugasKelurahanmenganjurkan

kepada calon peserta tersebut untuk segera melapor ke kantor cabang BPJS Kesehatan terdekat setelah terjadinya kegagalan proses penginputan pada aplikasi New eDabu agar langsung dapat di atasi dengan cepat dan tepat,

5. Terkait kegagalan login, sertapetugas sebaiknya menunggu beberapa menit dan mencoba ulang login kembali.

\section{DAFTAR PUSTAKA}

Daryanto dan Ismanto Setyobudi. 2014 Konsumen dan

PelayananPrima.Yogyakarta: Gava Media.

Khalil S, Munawwar. 2016. Pelayanan Kesehatan Peserta BPJS PBI di Rumah Sakit Umum Daerah Panglima Sebaya Kabupaten Paser.E-journalAdministrasi Negara. Vol. 4, no. 2, 4159-4171. Diambil dari: http://www.ejournal.an.fisipunmul.ac.id/ejournal/vol.4/no.2/inde x.html. (17 Mei 2018)

Maryam, Neneng Siti. 2018. Mewujudkan Good Governance Melalui Pelayanan Publik. Jurnal Ilmu Politik dan Komunikasi. Vol. 6, no. 1, 1-17. Diambil dari:http://www.repository.uniko m/ejournal/vol.6/no.1/index.html. (04 September 2018)

Mukarom, Zaenal dan Muhibudin Wijaya Laksana. 2015. Manajemen Pelayanan Publik. Bandung: Pustaka Setia.

Patmiarsih, R, Anthonius Margono dan Bambang Irawan. 2014. Implementasi Pelayanan Jaminan Kesehatan Daerah Pada RSUD Taman Husada Di Kota Bontang. Jurnal Administrative Reform. Vol. 2, no. 1, 48-60. Diambil dari: http://ejournal.an.fisip-

unmul.ac.id/ejournal/vol.4/no.2/inde x.html.

(07 September 2018)

Riyanto, Andi. 2018. Implikasi Kualitas Pelayanan Dalam Meningkatkan Kepuasan Pelanggan Pada PDAM Cibadak Sukabumi. Ecodemica. Vol. 2, no. 1, 117-124. Diambil dari: http://ejournal.bsi.ac.id/ejurnal/inde 
x.php/ecodemica/article/view/117/124. html. (15 Mei 2018)

Sugiyah. 2018. Kinerja Berbasis Pelayanan

Pada Perpustakaan Digital Kantor

Badan Pusat Statistik Provinsi DKI

Jakarta. Widya Cipta. Vol. 2, no. 1, 56-

61.

Diambil

dari:

http://www.ejournal.bsi.ac.id/ejurnal/in dex.php/widya-

cipta/article/view/56/61.html. (15 Mei 2018)

Umam, Khaerul. 2014. Manajemen Perkantoran. Bandung: Pustaka Setia.

\section{PROFIL PENULIS}

Syukron Sazly,SE,MMadalah seorang dosen Program Administrasi Bsnis Fakultas Ekonomi dan Bisnis (FEB) Universitas Bina Sarana Informatika, Jakarta. Yang sebelumnya adalah seorang professional perbankan.Menyelesaikan pendidikan sebagai Sarjana Ekonomi, dari Fakultas Ekonomi Universitas Udayana, sertaMagister Manajemen dari Universitas Mercu Buana . Penulis mengawali karir sebagai Management Trainee di Departemen Operasional Bank Danamon Indonesia, Tbk. Setelah tiga tahun sebagai professional untuk beberapa wilayah, penulis menutup karir di perbankan sebagai Kepala Pelaporan untuk Bank Indonesia (BI).
Himawan Pratamaadalah seorang alumni Universitas Bina Sarana Informatika, yang semasa kuliah aktif dalam berbagai kegiatan kemahasiswaan khususnya dalam Himpunan Mahasiswa Mahajemen Administrasi (HIMMA) Universitas Bina Sarana Informatika sebagai anggota. Penulis menyelesaikan pendidikan dasar di Sekolah Dasar Negeri (SDN) Duri Pulo yang diselesaikan pada tahun 2009. Setelah itu, penulis melanjutkan pendidikan di SMP Negeri 35 Jakarta dan lulus tahun 2012, Madrasah Aliyah Negeri (MAN) I Jakarta Barat, lulus tahun 2015. Saat ini Penulis bekerja sebagai karyawan swasta pada perusahaan swasta nasional yang berkedudukan di Jakarta. 
